Editor's Note: These short reviews of a recent paper in the Journal, written exclusively by graduate students or postdoctoral fellows, are intended to mimic the journal clubs that exist in your own departments or institutions. For more information on the format and purpose of the Journal Club, please see http://www.jneurosci.org/misc/ifa_features.shtml.

\title{
Searching for an Oddball: Neural Correlates of Singleton Detection Mode in Parietal Cortex
}

\author{
Michael J. Proul ${ }^{1}$ and John T. Serences ${ }^{2}$ \\ ${ }^{1}$ Institute of Experimental Psychology, Heinrich-Heine-University Düsseldorf, 40225 Düsseldorf, Germany, and ${ }^{2}$ Systems Neurobiology Laboratory, Salk \\ Institute for Biological Studies, La Jolla, California 92037 \\ Review of Balan and Gottlieb (http://www.jneurosci.org/cgi/content/full/26/36/9239)
}

We spend much of the day engaged in visual search tasks. Both the nature of the target and the context of the search can have a dramatic effect on search strategy and efficiency. Imagine looking for a single red apple among a pile of lemons, as depicted in Figure $1 A$; because there is only one red apple, searching for the unique item is an efficient strategy [referred to as a "singleton detection mode" $(\mathrm{SDM})]$. However, if the red apple is in a basket of lemons, oranges, and pears, then search must be based on a combination of specific features that distinguish the apple from its neighbors [color, texture, size, etc., which is referred to as "feature search mode" (FSM) (Bacon and Egeth, 1994)] (Fig. $1 B$ ). Thus, SDM relies primarily on "bottom-up" information to mark locations that contain unique objects, whereas FSM relies primarily on "top-down" information to specify target-defining features.

Although previous reports have demonstrated that top-down attention to a feature value (e.g., red) modulates the activity of neurons tuned to the attended feature (Martinez-Trujillo and Treue,

Received 0ct. 6, 2006; revised 0ct. 23, 2006; accepted 0ct. 23, 2006.

Correspondence should be addressed to either of the following: Michael Proulx, Institute of Experimental Psychology II, Building 23.03, 00.48, Universitätsstrasse 1, D-40225 Düsseldorf, Germany, E-mail: michael. proulx@uni-duesseldorf.de; or John Serences at his present address, University of California Irvine, Department of Cognitive Sciences, 3151 Social Science Plaza, Irvine, CA 92697-5100, E-mail: john.serences@uci.edu. DOI:10.1523/JNEUROSCI.4379-06.2006

Copyright $\odot 2006$ Society for Neuroscience $\quad$ 0270-6474/06/2612631-02\$15.00/0
2004), it is less clear how search for something "unique" might be implemented in the visual system. Because searching for a unique object requires adopting an attentional set that generalizes across basic feature categories, we might expect the neural correlate of SDM to be found in higher-order visual areas that are not strongly feature selective. New evidence reported by Balan and Gottlieb (2006) in The Journal of Neuroscience provides an intriguing neural mechanism for SDM in the lateral intraparietal area (LIP), a highorder visual area containing neurons that have clearly defined spatial receptive fields but weak feature preferences. The distribution of activity across LIP is thought to form an attentional priority map in which the current focus of spatial attention may be inferred based on the spatial receptive fields of the neurons with the highest instantaneous firing rate (Bisley and Goldberg, 2003). For example, an attended target stimulus evokes a stronger response in LIP neurons than an irrelevant distractor [Balan and Gottlieb, 2006, their Fig. $2 b$ (http://www.jneurosci.org/ cgi/content/full/26/36/9239\#F2)].

Balan and Gottlieb trained monkeys to search for an E or mirror-reversed $\mathrm{E}$ among other items with the same number of digital-clock-style line segments [Balan and Gottlieb, 2006, their Fig. 1 (http:// www.jneurosci.org/cgi/content/full/26/ 36/9239\#F1)]. In some blocks of trials, the target location was also marked by an additional visual perturbation (a single- ton stimulus that was unique in brightness, color, movement, etc.) that was presented either $200 \mathrm{~ms}$ before ( $-200 \mathrm{~ms})$, simultaneous with $(0 \mathrm{~ms})$, or $200 \mathrm{~ms}$ after $(+200 \mathrm{~ms})$ the onset of the search display. In other blocks, the singleton was always presented opposite the target. When the singleton occurred $200 \mathrm{~ms}$ before the search display at the target location, the monkeys were faster at reporting the direction of the target [Balan and Gottlieb, 2006, their Fig. 2a (http://www. jneurosci.org/cgi/content/full/26/36/ 9239\#F2)]. However, behavioral responses were slower on the $0 \mathrm{~ms}$ and +200 ms trials, no matter where the singleton was presented (i.e., at the target location or opposite the target location).

When the target and the singleton were presented at different locations (an OPPOSITE block), one would predict that the observer would adopt FSM because no single feature defined the target. However, in blocks in which the singleton and the target were presented at the same location (a SAME block), previous psychophysical studies predict that the observer should adopt SDM because the singleton reliably conveys information about the target location (Yantis and Egeth, 1999). Accordingly, firing rates in LIP were higher during SAME blocks compared with OPPOSITE blocks [Balan and Gottlieb, 2006, their Fig. 3 (http://www. jneurosci.org/cgi/content/full/26/36/ 9239\#F3)]. This multiplicative gain was spatially nonspecific and was evident well 
before the search array was presented (-400 ms) [Balan and Gottlieb, 2006, their Fig. 6a (http://www.jneurosci.org/ cgi/content/full/26/36/9239\#F6)]. The lack of spatial specificity is important because the location of the target was never known in advance. Because LIP is known to respond robustly to physically salient stimuli (Gottlieb et al., 1998), the lone singleton in the visual field on $-200 \mathrm{~ms}$ trials would evoke a robust response, and the multiplicative gain would serve to further boost this already strong response. Thus, if the distributed pattern of activity across LIP is tantamount to an attentional priority map, then the location of the singleton (and target) would be clearly prioritized in the search array, a supposition supported by the relatively fast reaction times (RTs) observed in this condition [Balan and Gottlieb, 2006, their Table 1 (http://www.jneurosci.org/cgi/content/ full/26/36/9239\#T1)].

However, SDM may not always be a good strategy. On one-third of the trials in a SAME block ( $-200 \mathrm{~ms}$ trials), the multiplicative gain modulation presumably facilitated search by enhancing foreknowledge of the location of the target, but, on the other two-thirds of the trials ( $0 \mathrm{~ms}$ and $+200 \mathrm{~ms}$ ), there was a behavioral cost (RTs were longer) [Balan and Gottlieb, 2006, their Fig. $2 a$ (http://www. jneurosci.org/cgi/content/full/26/36/ 9239\#F2)]. One explanation for this slowing on $0 \mathrm{~ms}$ and $+200 \mathrm{~ms}$ trials is that activity in LIP primarily reflects the spatial distribution of attention, whereas featureselective regions in early visual cortex (e.g., V1, V4v) have difficulty representing the identity of the target in the face of competition from the singleton. If true, then the contextual gain modulation might actually be invoked on $0 \mathrm{~ms}$ and +200 ms trials to partially combat this interference. On this account, the multiplicative gain modulation spreads to featureselective neurons in earlier visual areas, thereby partially insulating the target representation from interference by the masking singleton (although the slowing of RTs indicates a residual degree of interference). Because feature-based attention in known to enhance the response of neurons tuned to target-defining features (Martinez-Trujillo and Treue, 2004), one

A Singleton Detection Mode (SDM)

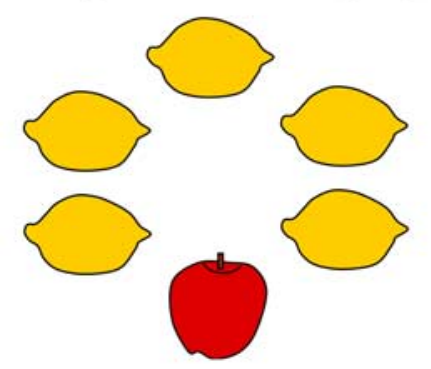

B Feature Search Mode (FSM)

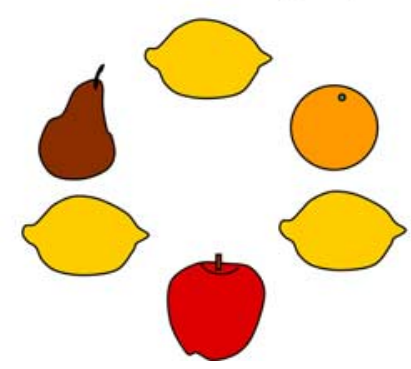

C

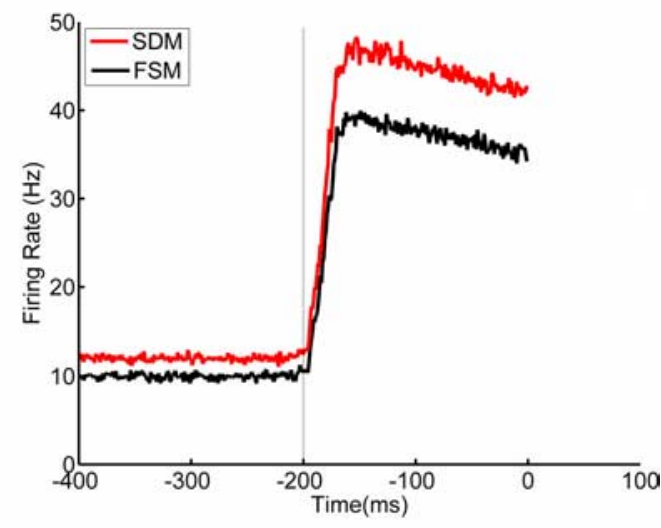

Figure 1. Search for the apple. $\boldsymbol{A}$, In this display, searching for the apple can be reduced to searching for the unique item; this attentional set is called singleton detection mode. $\boldsymbol{B}$, One cannot search for the unique item here but rather only for the features that define the target (feature search mode). C, Plot of simulated data based on Balan and Gottlieb (2006), their Figure 6a (http://www.jneurosci.org/cgi/content/full/26/36/9239\#F6). Evoked responses to the singleton on $-200 \mathrm{~ms}$ trials are plotted; the response is higher (by a multiplicative gain factor) during SAME blocks (SDM) compared with OPPOSITE blocks (FSM). In SDM, the multiplicative gain enhances the already robust response to the singleton, serving to further enhance the attentional priority of this location in the search array, which in turn may facilitate target localization.

clear prediction is that a spatially nonspecific multiplicative gain factor should further bias the population response in earlier visual areas in favor of neurons representing the identity of the target.

Is the contextual gain modulation observed on SAME trials really the neural correlate of searching for an oddball? The results at this point are certainly consistent with this notion (Fig. 1C). However, there are two potential reasons for applying the contextual gain on SAME blocks in the present study: boosting the response to a predictive singleton on $-200 \mathrm{~ms}$ trials and insulating the target representation from competition on $0 \mathrm{~ms}$ and $+200 \mathrm{~ms}$ trials. Of course, it is possible that observers adopted SDM to exploit the singleton on $-200 \mathrm{~ms}$ trials, without regard to the potential utility of the multiplicative gain on $0 \mathrm{~ms}$ or $+200 \mathrm{~ms}$ trials. If a spatially nonspecific multiplicative gain factor is confirmed to be a neural mechanism mediating SDM, then these data provocatively suggest that a top-down attentional set (i.e., the adoption of a contextual gain modulation) plays an important role in detecting a unique item, which was previously thought to be a strictly bottom-up process.

\section{References}

Bacon WF, Egeth HE (1994) Overriding stimulus-driven attentional capture. Percept Psychophys 55:485-496.

Balan P, Gottlieb J (2006) Integration of exogenous input into a dynamic salience map revealed by perturbing attention. J Neurosci 26:9239-9249.

Bisley JW, Goldberg ME (2003) Neuronal activity in the lateral intraparietal area and spatial attention. Science 299:81-86.

Gottlieb J, Kusunoki M, Goldberg ME (1998) The representation of visual salience in monkey parietal cortex. Nature 391:481-484.

Martinez-Trujillo JC, Treue S (2004) Featurebased attention increases the selectivity of population responses in primate visual cortex. Curr Biol 14:744-751.

Yantis S, Egeth HE (1999) On the distinction between visual salience and stimulus-driven attentional capture. J Exp Psychol Hum Percept Perform 25:661-676. 